$4.28 \times 10^{9}$ cells $/ \mathrm{L}$, a hemoglobin level of $86 \mathrm{~g} / \mathrm{L}$, and a leukocyte count of $8.28 \times 10^{9}$ cells/L with $17 \%$ neutrophils and $78 \%$ lymphocytes.

The patient was given symptomatic supportive treatment, methylprednisolone sodium succinate, and $5 \mathrm{~g}$ of $\gamma$-globulin. He was not given any antimicrobial drugs. On August 4, he was discharged from hospital after symptoms had resolved.

In conclusion, our results confirm that mimivirus is an unlikely cause of human respiratory infections in China, as reported in other countries (5-9). Sporadic detection of mimivirus in 1 child who was born with a compromised respiratory system and had numerous hospitalizations was most likely caused by colonization of the child with this virus during numerous hospitalizations and critical care stays. In addition, parainfluenza virus 3 and bocavirus were detected in the mimivirus-positive child. Because parainfluenza virus 3 causes pneumonia and bocavirus causes infections with respiratory symptoms, particularly in children of his age, these 2 pathogens probably caused the illness in the child.

\section{Acknowledgments}

We thank all patients, their families, and collaborating clinicians for participating in this study.

This study was supported by grants from the National Natural Science Foundation (no. 81222037) and China Mega-Project on Infectious Disease Prevention (no. 2013ZX10004202).

\section{References}

1. Raoult D, Audic S, Robert C, Abergel C, Renesto P, Ogata H, et al. The 1.2-megabase genome sequence of mimivirus. Science. 2004;306:1344-50. http://dx.doi.org/10.1126/science.1101485

2. Abergel C, Legendre M, Claverie JM. The rapidly expanding universe of giant viruses: mimivirus, pandoravirus, pithovirus and mollivirus. FEMS Microbiol Rev. 2015;39:779-96. http://dx.doi.org/10.1093/femsre/fuv037

3. La Scola B, Marrie TJ, Auffray JP, Raoult D. Mimivirus in pneumonia patients. Emerg Infect Dis. 2005;11:449-52. http://dx.doi.org/10.3201/eid1103.040538

4. Saadi H, Pagnier I, Colson P, Cherif JK, Beji M, Boughalmi M, et al. First isolation of mimivirus in a patient with pneumonia. Clin Infect Dis. 2013;57:e127-34. http://dx.doi.org/10.1093/cid/cit354

5. Larcher C, Jeller V, Fischer H, Huemer HP. Prevalence of respiratory viruses, including newly identified viruses, in hospitalised children in Austria. Eur J Clin Microbiol Infect Dis. 2006;25:681-6. http://dx.doi.org/10.1007/s10096-006-0214-z

6. Dare RK, Chittaganpitch M, Erdman DD. Screening pneumonia patients for mimivirus. Emerg Infect Dis. 2008;14:465-7. http://dx.doi.org/10.3201/eid1403.071027

7. Vanspauwen MJ, Franssen FM, Raoult D, Wouters EF, Bruggeman CA, Linssen CF. Infections with mimivirus in patients with chronic obstructive pulmonary disease. Respir Med. 2012;106:1690-4. http://dx.doi.org/10.1016/j.rmed.2012.08.019

8. Costa C, Bergallo M, Astegiano S, Terlizzi ME, Sidoti F, Solidoro $\mathrm{P}$, et al. Detection of mimivirus in bronchoalveolar lavage of ventilated and nonventilated patients. Intervirology. 2012;55:3035. http://dx.doi.org/10.1159/000329088

9. Vanspauwen MJ, Schnabel RM, Bruggeman CA, Drent M, van Mook WN, Bergmans DC, et al. Mimivirus is not a frequent cause of ventilator-associated pneumonia in critically ill patients. $\mathrm{J}$ Med Virol. 2013;85:1836-41. http://dx.doi.org/10.1002/jmv.23655

10. Pelletier N, Raoult D, La Scola B. Specific recognition of the major capsid protein of Acanthamoeba polyphaga mimivirus by sera of patients infected by Francisella tularensis. FEMS Microbiol Lett. 2009;297:117-23. http://dx.doi.org/10.1111/j.15746968.2009.01675.x

Address for correspondence: Wei Liu or Wu-Chun Cao, State

Key Laboratory of Pathogen and Biosecurity, Beijing Institute of Microbiology and Epidemiology, 20 Dong-Da St, Fengtai District; Beijing 100071, China; email: lwbime@163.com or caowc@bmi.ac.cn

\title{
Severe Pneumonia Associated with Adenovirus Type 55 Infection, France, 2014
}

\section{Jérémy Lafolie, Audrey Mirand, Maud Salmona, Alexandre Lautrette, Christine Archimbaud, Amélie Brebion, Christel Regagnon, Martine Chambon, Séverine Mercier-Delarue, Jérôme Le Goff, Cécile Henquell}

\author{
Author affiliations: Centre Hospitalier Universitaire Gabriel \\ Montpied, Clermont-Ferrand, France (J. Lafolie, A. Mirand, \\ A. Lautrette, C. Archimbaud, A. Brebion, C. Regagnon, \\ M. Chambon, C. Henquell); Université d'Auvergne, \\ Clermont-Ferrand (J. Lafolie, A. Mirand, A. Lautrette, \\ C. Archimbaud, M. Chambon, C. Henquell); Hôpital Saint-Louis, \\ Paris, France (M. Salmona, S. Mercier-Delarue, J. Le Goff); \\ Université Paris Diderot, Paris (M. Salmona, J. Le Goff)
}

DOI: http://dx.doi.org/10.3201/eid2211.160728

To the Editor: Human adenoviruses (HAdVs) comprise 70 recognized genotypes (as of February 15, 2016; http://hadvwg.gmu.edu/) and are frequently associated with mild and acute upper respiratory tract infections, depending on virus type and host immune status (1). HAdV type 55 (HAdV-55) has recently reemerged as a highly virulent pathogen, causing severe and sometimes fatal pneumonia among immunocompetent adults, particularly in Asia (2-4). Formerly known as HAdV-11a, HAdV-55 is a genotype resulting from recombination between HAdV-11 and HAdV-14 (5). We report 2 cases of severe pneumonia associated with HAdV-55 infection in France.

In November 2014, two immunocompetent women, 71 (patient A) and 36 (patient B) years of age, sought care 4 days apart at the emergency unit of the University 
Hospital of Clermont-Ferrand, France, for an influenzalike syndrome characterized by fever, cough, and dyspnea. Laboratory investigations at admission revealed thrombocytopenia (98 and $88 \times 10^{9}$ thrombocytes/L for patients $\mathrm{A}$ and $\mathrm{B}$, respectively; reference range 150-450 $\times$ $10^{9}$ thrombocytes/L) and elevated C-reactive protein concentrations $(71.6$ and $45.8 \mathrm{mg} / \mathrm{L}$, respectively; reference range $<3 \mathrm{mg} / \mathrm{L}$ ). Chest radiographs and thoracic tomodensitometry images showed acute left lobar pneumonia in each patient. Therapy with intravenous antimicrobial drugs (cefepime and levofloxacin) and oxygen was initiated. Patient A was transferred to the intensive care unit 4 days after admission because of unimproved respiratory function; patient B was transferred 5 days after admission because of acute respiratory distress syndrome.

Results for all bacteriologic analyses were negative (blood cultures, bronchoalveolar lavage fluid cultures, PCR for Mycobacterium tuberculosis [Xpert MTB/RIF; Cepheid, Sunnyvale, CA, USA] of bronchoalveolar lavage fluid, and urinary antigen testing [BinaxNOW Legionella and Streptococcus pneumoniae; Alere, Scarborough, ME, USA]). No specific antibodies were detected against Chlamydia pneumoniae (Anti-C. pneumoniae; Euroimmun,
Lübeck, Germany) and Mycoplasma pneumoniae (Platelia M. pneumoniae IgM; Bio-Rad, Hercules, CA, USA). For each patient, HAdV was the only pathogen detected in nasopharyngeal secretions collected at admission and in bronchoalveolar lavage fluids collected while in the intensive care unit (molecular multiplex assay [FilmArray Respiratory Panel; bioMérieux, Durham, NC, USA]). HAdV DNA was also detected in whole blood (Adenovirus R-gene; bioMérieux); viral load was 280,524 copies/mL for patient A 9 days after hospital admission and 951,146 copies/mL for patient B 4 days after admission. During hospitalization, transient hepatitis developed in each patient; serum aspartate aminotransferase levels were elevated up to 6-10 times reference range, and leukocyte counts indicated leukopenia $\left(2.17\right.$ and $1.28 \times 10^{9} / \mathrm{L}$ for patients $\mathrm{A}$ and $\mathrm{B}$, respectively; reference range 4-10 $\times 10^{9} / \mathrm{L}$ ). Patient B had acute pancreatitis and hyperlipasemia (lipase 1,697 UI/L; reference range 73-393 UI/L). Healthy respiratory function was restored for both patients, who were discharged 26 (patient A) and 19 (patient B) days after admission.

A partial region of the hexon gene was amplified and sequenced from DNA extracts of respiratory and blood
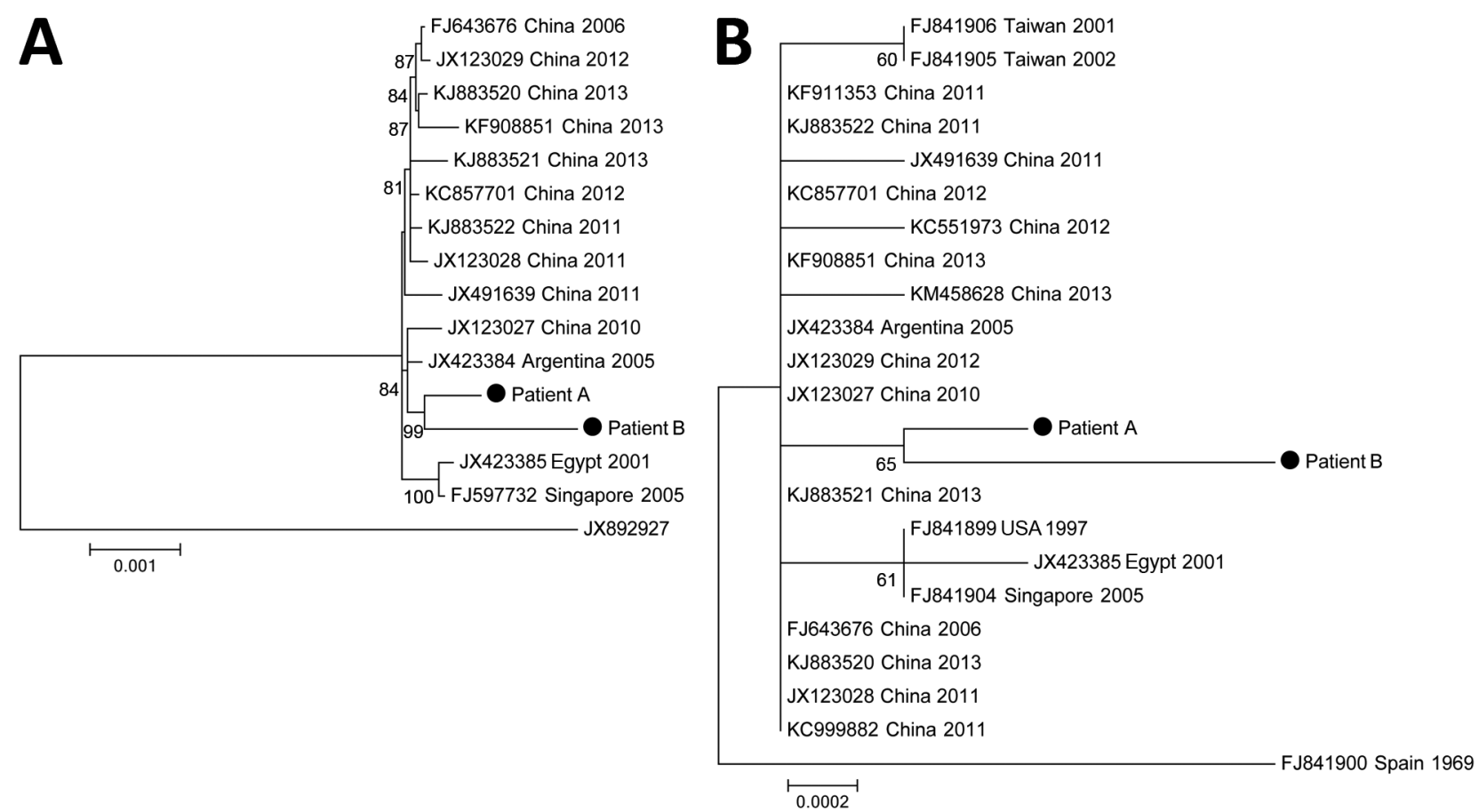

Figure. Phylogeny of 13 complete-genome sequences of human adenovirus type $55(A)$ and of 21 sequences of hexon genes (B). The complete genome tree $(A)$ is rooted to a human adenovirus type 14 isolate (GenBank accession no. JX892927). The strains from patients $A$ and $B$ (immunocompetent women with human adenovirus infection) reported in this study are indicated. The phylogenetic tree was calculated by using the maximum-likelihood method in MEGA6 (http://www.megasoftware.net). The best algorithm was chosen by the criterion score of the Bayesian information criteria. The statistical robustness of branches was estimated by 1,000 bootstraps. Only bootstrap values $>70 \%$ are indicated. The tree is drawn to scale; branch lengths are measured in number of substitutions per site (scale bar). All positions containing gaps and missing data were eliminated. The sequence of the hexon gene from patient B was partially complete $(2,821 / 2,841,99.3 \%)$. 
samples, as previously described (6). Phylogenetic analysis with strains representing all HAdV genotypes identified the viruses as HAdV-55 (data not shown). We performed complete-genome sequencing, which is now recommended for confirmation of HAdV type, by using next-generation sequencing from blood samples (online Technical Appendix, http://wwwnc.cdc.gov/EID/article/22/11/16-0728Techapp1.pdf). Genome coverage $(34,755 \mathrm{nt})$ was $99.1 \%$ (patient A) and 96.1\% (patient B). Phylogenetic analysis showed that the sequences of the isolates from the 2 patients clustered together (bootstrap 99\%) and were genetically more closely related to the sequences of the CQ-814 strain isolated in China in 2010 and the strain from Argentina (GenBank accession no. JX423384) (Figure, panel A). To investigate genetic relationships with more strains from distant geographic areas, we performed phylogenetic analyses with all available sequences of the hexon gene of HAdV-55 strains. However, because diversity of this gene between strains was low, we could not determine the geographic origin of the strains from France, which were genetically distant from the strain isolated in Spain in 1969 (Figure, panel B).

Over the past 10 years, reports of HAdV-55 have been increasing in Asia during outbreaks of respiratory diseases that in some cases led to severe pneumonia and deaths in immunocompetent adults and children $(2-4,7,8)$. Of the 969 cases of community-acquired pneumonia in adults, 48 (5\%) were associated with HAdVs; HAdV-55 was identified in $21(43.8 \%)$ of these patients (7). For the 2 patients we report, clinical features were similar to those described elsewhere $(4,8)$. Neither patient had traveled recently, and the 2 patients had not had contact with each other. Analysis of complete genomic sequences showed that the viruses infecting the patients were distinguishable from strains previously isolated in other countries. HAdV-55 could thus have been circulating in France for several years. Since its first detection in Spain in 1969 (9), HAdV-55 has been reported only 1 time in Europe, in Germany in 2004 (10).

Because most HAdV infections are asymptomatic and respiratory virus screening in routine practice does not systematically include HAdV detection, the true prevalence and clinical effect of HAdV-55 infection has probably been underestimated. The involvement of virus of this genotype in severe pneumonia emphasizes the need to reinforce HAdV surveillance by including HAdV genome detection and genotyping (if positive) in the documentation of severe respiratory infections.

\section{Acknowledgments}

We are grateful to the technicians of the virology laboratory of the University Hospital of Clermont-Ferrand for excellent technical assistance in adenovirus genome detection and genotyping. We thank Jeffrey Watts for revision of the manuscript in English.

\section{References}

1. Lion T. Adenovirus infections in immunocompetent and immunocompromised patients. Clin Microbiol Rev. 2014;27:441-62. http://dx.doi.org/10.1128/CMR.00116-13

2. Kajon AE, Dickson LM, Metzgar D, Houng H-S, Lee V, Tan B-H. Outbreak of febrile respiratory illness associated with adenovirus 11a infection in a Singapore military training camp. J Clin Microbiol. 2010;48:1438-41. http://dx.doi.org/10.1128/JCM.01928-09

3. Lu Q-B, Tong Y-G, Wo Y, Wang H-Y, Liu E-M, Gray GC, et al. Epidemiology of human adenovirus and molecular characterization of human adenovirus 55 in China, 2009-2012. Influenza Other Respir Viruses. 2014;8:302-8. http://dx.doi.org/10.1111/irv.12232

4. Zhang S-Y, Luo Y-P, Huang D-D, Fan H, Lu Q-B, Wo Y, et al. Fatal pneumonia cases caused by human adenovirus 55 in immunocompetent adults. Infect Dis (Lond). 2016;48:40-7. http://dx.doi.org/10.3109/23744235.2015.1055585

5. Seto D, Jones MS, Dyer DW, Chodosh J. Characterizing, typing, and naming human adenovirus type 55 in the era of whole genome data. $\mathrm{J}$ Clin Virol. 2013;58:741-2. http://dx.doi.org/10.1016/j.jcv.2013.09.025

6. Lu X, Erdman DD. Molecular typing of human adenoviruses by PCR and sequencing of a partial region of the hexon gene. Arch Virol. 2006;151:1587-602. http://dx.doi.org/10.1007/s00705-005-0722-7

7. Cao B, Huang G-H, Pu Z-H, Qu J-X, Yu X-M, Zhu Z, et al. Emergence of community-acquired adenovirus type 55 as a cause of community-onset pneumonia. Chest. 2014;145:79-86. http://dx.doi.org/10.1378/chest.13-1186

8. Sun B, He H, Wang Z, Qu J, Li X, Ban C, et al. Emergent severe acute respiratory distress syndrome caused by adenovirus type 55 in immunocompetent adults in 2013: a prospective observational study. Crit Care. 2014;18:456. http://dx.doi.org/10.1186/s13054-014-0456-6

9. Hierholzer JC, Pumarola A, Rodriguez-Torres A, Beltran M. Occurrence of respiratory illness due to an atypical strain of adenovirus type 11 during a large outbreak in Spanish military recruits. Am J Epidemiol. 1974;99:434-42.

10. Chmielewicz B, Benzler J, Pauli G, Krause G, Bergmann F, Schweiger B. Respiratory disease caused by a species B2 adenovirus in a military camp in Turkey. J Med Virol. 2005; 77:232-7. http://dx.doi.org/10.1002/jmv.20441

Address for correspondence: Jérémy Lafolie, Service de Virologie Médicale, Centre Hospitalier Universitaire Gabriel Montpied, 58 Rue Montalembert, Clermont-Ferrand, CEDEX 63003, France; email: jlafolie@chu-clermontferrand.fr

\section{Spotted Fever Group Rickettsia in the Pampa Biome, Brazil, 2015-2016}

\author{
Bárbara Weck, Bruno Dall'Agnol, Ugo Souza, \\ Anelise Webster, Barbara Stenzel, \\ Guilherme Klafke, João Ricardo Martins, José Reck
}

Author affiliations: Instituto de Pesquisas Veterinárias Desidério Finamor, Eldorado do Sul, Brazil (B. Weck, B. Dall'Agnol, U. Souza, A. Webster, G. Klafke, J.R. Martins, J. Reck); Centro Estadual de Vigilância em Saúde, Porto Alegre, Brazil (B. Stenzel)

DOI: http://dx.doi.org/10.3201/eid2211.160859 